\title{
Studies on the Metabolic Error in Refsum's Disease*
}

\author{
Daniel Steinberg, $†$ Charles E. Mize, Joel Avigan, Henry M. Fales, \\ Lorentz Eldjarn, Kenneth Try, Oddvar Stokke, and \\ SigVald ReFsum \\ (From the Laboratory of Metabolism, National Heart Institute, Bethesda, Md., and the \\ Institute of Clinical Biochemistry and Department of Neurology, University of \\ Oslo Rikshospitalet, Oslo, Norway)
}

\begin{abstract}
Summary. Studies utilizing mevalonic acid-2- ${ }^{14} \mathrm{C}$ and $\mathrm{D}_{2} \mathrm{O}$ as precursors failed to provide evidence for an appreciable rate of endogenous biosynthesis of phytanic acid in a patient with Refsum's disease.

Orally administered tracer doses of phytol-U- ${ }^{14} \mathrm{C}$ were well absorbed both by seven normal control subjects (61 to $94 \%$ ) and by two patients with Refsum's disease (74 and $80 \%$ ).

The fraction of the absorbed dose converted to ${ }^{14} \mathrm{CO}_{2}$ in 12 hours was 3.5 and $5.8 \%$ in Refsum's disease patients and averaged $20.9 \%$ in seven control subjects.

Labeled phytanic acid was demonstrated in the plasma of both control subjects and patients given phytol-U- ${ }^{14} \mathrm{C}$, establishing phytol in the diet as a potential precursor of phytanic acid. This labeled phytanic acid had disappeared almost completely from the plasma of the seven control subjects by 24 to 48 hours, whereas it persisted at high concentrations in the plasma of the two patients for many days.

We conclude that the phytanic acid accumulating in Refsum's disease is primarily of exogenous origin and that patients with Refsum's disease have a relative block in the degradation of phytanic acid and possibly other similar branched-chain compounds. This may relate to a deficiency in mechanisms for release of phytanic acid from stored ester forms or, more probably, to reactions essential to oxidative degradation of the carbon skeleton.
\end{abstract}

\section{Introduction}

Heredopathia atactica polyneuritiformis was first reported as a clinical entity by Refsum in 1945 (1). The prominent features of the syndrome include atypical retinitis pigmentosa, hypertrophic peripheral neuropathy, cerebellar ataxia, nerve deafness, and elevated cerebrospinal fluid protein concentration with albuminocytologic dissociation (2). Although only some 40 cases have been reported, it seems fairly certain that the disease is genetic in origin and transmitted in an autosomal recessive manner (2-4).

\footnotetext{
* Submitted for publication August 1, 1966; accepted November 3, 1966.

$\dagger$ Address requests for reprints to Dr. Daniel Steinberg, Laboratory of Metabolism, National Heart Institute, Bethesda, Md. 20014.
}

In 1963 Klenk and Kahlke (5) found that the blood and tissues of patients with Refsum's disease contained high concentrations of an unusual branched-chain fatty acid-phytanic acid (3,7,11, 15-tetramethylhexadecanoic acid). In the liver of the first patient studied chemically post-mortem, phytanic acid accounted for over $50 \%$ of total fatty acids; the relative concentration of phytanic acid in kidney lipids was almost as great (5). Very similar results in tissues of another patient have been reported by Hansen (6). Phytanic acid in the plasma can account for anywhere from 3 to $25 \%$ of total fatty acids (7-9). The present studies were undertaken to explore the origins of the phytanic acid and the nature of the metabolic error leading to its accumulation.

The polyisoprenoid structure of phytanic acid suggested that it might be biosynthesized by way 
of mevalonic acid in analogy with the biosynthesis of the branched-chain skeleton of farnesyl pyrophosphate (10) (Figure 1). The formation of geranylgeranyl pyrophosphate by addition of a fourth isopentenyl pyrophosphate unit to farnesyl pyrophosphate is a normal step in plants and in yeast on the pathway to carotene formation (11). Nandi and Porter have shown that a pig liver preparation can catalyze this reaction (12). As shown in Figure 1, phytanic acid could be formed from geranylgeranyl pyrophosphate (after elimination of the pyrophosphate group) by reduction of its four double bonds and oxidation of the alcohol function to a carboxylic acid. Although there is no evidence that geranylgeranyl pyrophosphate is formed in significant amounts by mammals under ordinary circumstances, it seemed possible that a genetic error could evoke or accentuate such a pathway, e.g., by inhibiting the rate of condensation of farnesyl pyrophosphate with itself to form squalene. If there were a metabolic block in the breakdown of phytanic acid, then even a limited rate of synthesis could lead to accumulation of the product. One purpose of the present studies was to test for biosynthesis.

Animal studies established that phytol, ubiquitously present in the diet as a component of the chlorophyll molecule, can readily be converted to phytanic acid (13-16). Phytanic acid itself is also present in the diet as a minor component in butterfat (17) and ruminant body fats $(18,19)$. Normal human and animal sera contain phytanic acid but only at very low concentrations $(20,21)$. However, when either phytol or phytanic acid is fed to animals in sufficiently large dosage, phytanic acid accumulates in blood and tissues, and the concentrations can reach levels comparable to those observed in patients with Refsum's disease (13$15,22)$. If there were a metabolic block in the degradation of phytanic acid, even a low intake of these potential precursors could cause accumulation in affected patients. A second major purpose of the present studies was to explore the metabolism of phytol and phytanic acid in patients with Refsum's disease. Results of these studies have been reported in preliminary form (23-25).

\section{Methods}

The case histories of our two patients with Refsum's disease (T.E. and K.M.) have been presented in detail elsewhere (9). A summary of some pertinent laboratory findings at the time of the present studies is given in

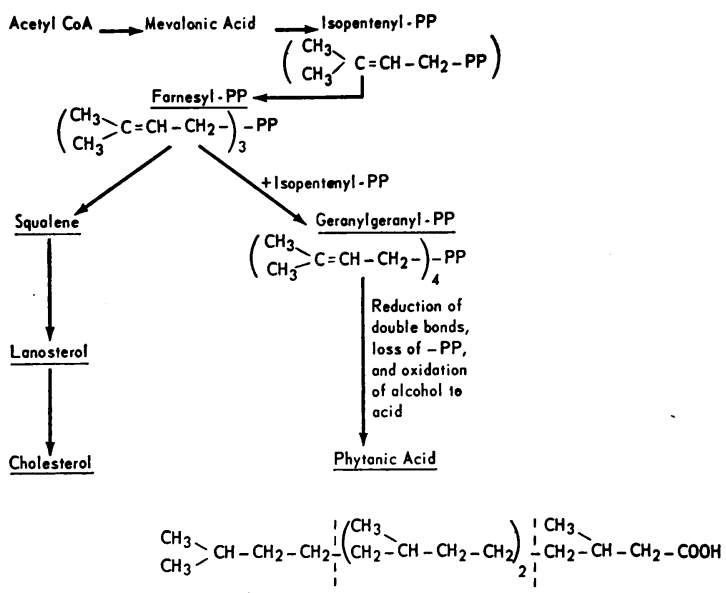

Fig. 1. Schematic Representation of the biosynTHETIC ROUTE TO CHOLESTEROL FROM ACETYL-COA, AND OF A POSSIBLE PATHWAY TO PHYTANIC ACID VIA GERANYLGERANYL PYROPHOSPHATE.

Table I. The patients were under observation at Rikshospitalet in Oslo; seven normal volunteers were studied at the Clinical Center in Bethesda.

At the time of the phytol- $\mathrm{U}_{-}^{14} \mathrm{C}$ and $\mathrm{D}_{2} \mathrm{O}^{1}$ studies, the patients were on a vegetable-free, low fat diet; on the day preceding the study and for 7 days thereafter, the normal subjects were given a diet lacking green vegetables and dairy products but containing adequate amounts of vitamins and iron. The radioactive preparations were administered after a 12-hour overnight fast, food being withheld for an additional 3 hours after administration. Phytol-U- ${ }^{14} \mathrm{C}$ was given orally, dissolved in $10 \mathrm{ml}$ of corn oil or olive oil. The preparation of uniformly labeled phytol- ${ }^{14} \mathrm{C}$ has been described elsewhere $(13,16)$; the samples used were 93 to $98 \%$ pure by radioassay. Mevalonate- $2-{ }^{14} \mathrm{C}$ (98.5\% pure by radioassay) was obtained as the dibenzylethylenediamine salt, ${ }^{2}$ converted to the potassium salt, and given intravenously.

At specified times, respiratory gases were collected over accurately measured 2-minute intervals into evacuated Douglas bags with subjects in a resting state. The total content of each Douglas bag was passed through $5 \mathrm{~N} \mathrm{NaOH}$ for absorption of $\mathrm{CO}_{2}$. The gas train included a $\mathrm{Ba}(\mathrm{OH})_{2}$ trap to detect any loss of $\mathrm{CO}_{2}$ in the initial absorption; any $\mathrm{BaCO}_{3}$ formed was also analyzed for radioactivity. The solution containing $\mathrm{Na}_{2}{ }^{14} \mathrm{CO}_{3}$ was counted directly on anthracene crystals (26) or was treated with saturated barium hydroxide or barium chloride to precipitate $\mathrm{Ba}^{14} \mathrm{CO}_{3}$ quantitatively. The barium carbonate was either finely ground and suspended in $5 \%$ Cab-O-Sil 3 for radioassay (27) or was treated with sulfuric acid with quantitative collection of the released ${ }^{14} \mathrm{CO}_{2}$ into phenethylamine ${ }^{4}$ scintillation medium (28).

1 Deuterium oxide was a generous gift of Norsk $\mathrm{Hy}$ dro-Electrisk Kvaelstofaktieselskab, Oslo, Norway.

2 New England Nuclear Corp., Boston, Mass.

3 Packard Instrument Co., Downers Grove, Ill.

4 Eastman Organic Chemicals, Rochester, N. Y. 
TABLE I

Concentrations of plasma components in two patients with Refsum's disease*

\begin{tabular}{|c|c|c|}
\hline & T.E. & K.M. \\
\hline Sex & F & $\mathbf{M}$ \\
\hline Age & 44 & 25 \\
\hline \multicolumn{3}{|l|}{ Phytanic acid, $\mathrm{mg} / 100 \mathrm{ml}$} \\
\hline Total & 27 & \\
\hline $\begin{array}{l}\text { In phospholipids } \\
\text { In triglycerides }\end{array}$ & & $\begin{array}{l}10-12 \\
25-27\end{array}$ \\
\hline Cholesterol, $\mathrm{mg} / 100 \mathrm{ml}$ & 230 & 238 \\
\hline Phospholipids, $\mathrm{mg} / 100 \mathrm{ml}$ & 214 & 235 \\
\hline Triglycerides, $\mathrm{mg} / 100 \mathrm{ml}$ & 147 & 147 \\
\hline Free fatty acids, $m E q / m l$ & 0.68 & 0.33 \\
\hline Total protein, $\mathrm{g} / 100 \mathrm{ml}$ & 7.7 & 7.3 \\
\hline Urea, $\mathrm{mg} / 100 \mathrm{ml}$ & 22 & 28 \\
\hline Alkaline phosphatase, Bodansky $U / \mathrm{ml}$ & 5.2 & 5.2 \\
\hline Lactic dehydrogenase, Wróblewski $U / m l$ & 440 & 130 \\
\hline Magnesium, $m E q / L$ & 1.8 & 1.4 \\
\hline Ceruloplasmin, $\mathrm{mg} / 100 \mathrm{ml}$ & 17 & 17 \\
\hline
\end{tabular}

* Other plasma values within normal ranges: thymol turbidity, serum glutamic oxaloacetic transaminase, serum glutamic pyruvic transaminase, creatinine, calcium, phosphorus, acid phosphatase, potassium, chloride, bicarbonate, bilirubin, serum iron and total iron-binding capacity, uric acid, and erythrocyte potassium and sodium. A normal amino acid chromatographic pattern was found in both patients in serum and urine. Cerebrospinal fluid protein values in T.E. and K.M., respectively, were 68 and $120 \mathrm{mg}$ per $100 \mathrm{ml}$.

Results obtained by any of these methods were in good agreement; recovery of radioactivity from known standards of $\mathrm{Ba}_{2}{ }^{14} \mathrm{CO}_{3}$ was greater than $95 \%$. Internal standards were used to correct for quenching, and all results were corrected to the same efficiency. All radioactive counting was done in a Packard Tri-Carb scintillation counter. All solvents and reagents were redistilled before use.

Total urine and fecal collections were made for at least 4 days in most cases. Urine samples were prepared directly for radioassay in a dioxane-containing scintillation medium (29); fecal lipid radioactivity was determined from a sample of uniformly homogenized and suspended feces (30). Total lipid radioactivity in feces was subtracted from the dose given to estimate the amount of labeled phytol absorbed. As shown in animal studies, some phytol radioactivity appears in bile (31), and the data for absorption calculated in this way therefore represent minimal values.

Venous blood samples were drawn into heparinized syringes. Plasma lipids were extracted according to the method of Folch, Lees, and Sloane Stanley (32), and the chloroform phase was analyzed for cholesterol (33), phospholipids (34), and triglycerides (35). Total lipid radioactivity was determined directly from a sample added to $0.4 \%$ diphenyloxazole in toluene. Other lipid samples were saponified and further fractionated by sol- vent partition and either thin layer or gas-liquid chromatography, or both, as described elsewhere $(13,15)$. Total plasma nonsaponifiable lipids were subjected to thin layer chromatography (TLC) in benzene-ethyl acetate 4:1 to separate phytol and cholesterol. In the studies with mevalonate- $2-{ }^{14} \mathrm{C}$, cholesterol isolated in this way accounted for $94 \%$ of the nonsaponifiable fraction. Fatty acids were extracted with hexane and ether from the acidified mixture after saponification, methylated, and chromatographed on thin layers of silicic acid with benzene-hexane 2:1. The branched-chain acids migrate slightly faster than straight-chain acids in this system, but are not completely resolved from them. When the phytanic acid-containing band was checked by gasliquid chromatography, the methyl phytanate peak generally accounted for $90 \%$ or more of the total, but there were always a few smaller peaks corresponding to saturated straight-chain acids.

Body water enrichment with deuterium in subject T.E. was obtained by giving an initial dose of $400 \mathrm{ml}$ of $50 \% \mathrm{D}_{2} \mathrm{O}$ by mouth (divided in three portions), an amount calculated to reach approximately 0.5 atom $\%$ excess enrichment. Thereafter, single daily doses $(40 \mathrm{ml}$ of $50 \% \mathrm{D}_{2} \mathrm{O}$ ) calculated to replace deuterium lost in turnover of body water were administered to maintain this enrichment. Deuterium enrichment in the water of daily urine samples and approximately biweekly serum samples was determined by infrared spectroscopy (36) in a Beckman IR-7 spectrometer. Atom per cent excess deuterium was held in a narrow range between 0.44 and 0.54 , averaging 0.49 over the 130 days of study. Enrichment in plasma cholesterol and in plasma phytanic acid was determined by mass spectrometry with an Associated Electronics Industries MS-9 high resolution instrument.

Cholesterol was purified for mass spectrometry from the plasma nonsaponifiable fraction via the digitonide. Phytanic acid was isolated from the plasma saponifiable fraction by TLC of the methyl esters as described above. To remove any co-chromatographing impurities, we further purified the methyl phytanate isolated by TLC by preparative gas-liquid chromatography. The mass spectra obtained of the purified plasma phytanic acid samples were identical with the spectrum of synthetic methyl phytanate. Free cholesterol and methyl phytanate were introduced directly into the ionization chamber via a probe inlet system. The ratio of the intensity of the peak of deuterium-containing molecules $(\mathrm{m} / \mathrm{e}+1)$ to that of the parent peak $(\mathrm{m} / \mathrm{e})$, corrected for the natural abundance of $(\mathrm{m} / \mathrm{e}+1)$ molecules (due to ${ }^{13} \mathrm{C},{ }^{2} \mathrm{H},{ }^{17} \mathrm{O}$ ), was used to calculate atoms per cent excess deuterium. At the low enrichments encountered, the abundance of $(\mathrm{m} / \mathrm{e}+2)$ species could be neglected. The breakdown of methyl phytanate in the ionizing beam of the spectrometer gives rise to a high yield of a fragment of $\mathrm{m} / \mathrm{e}=101$, resulting from splitting just beyond the first branchmethyl group:<smiles>COC(=O)CC(C)CCCC(C)CCCC(C)CCCC(C)C</smiles> 


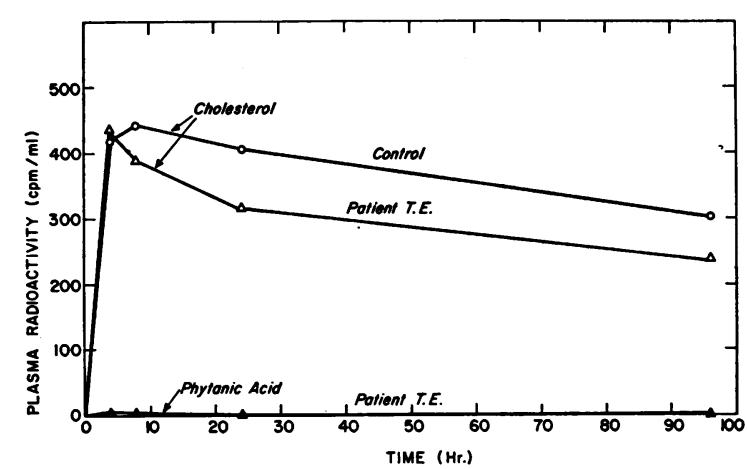

Fig. 2. InCORPORATION OF MEVALONIC ACID-2- ${ }^{14} \mathrm{C}$ INTO PLASMA CHOLESTEROL OR PHYTANIC ACID IN A PATIENT (T.E.) WITh Refsum's disease aNd IN A NORMAL (CONTROL) SUBJECT.

The intensity ratio $102: 101$ was also calculated, thus determining specifically the extent to which enrichment was localized in this terminal fragment of the molecule.

\section{Results}

Attempts to demonstrate endogenous biosynthesis. Patient T.E. was first studied in October 1964 , when she was on a standard hospital diet. DL-Mevalonic acid-2-14C $(25 \mu \mathrm{c})$ was given intravenously after an overnight fast, and blood samples were drawn from another vein at timed intervals. As shown in Figure 2, incorporation into plasma cholesterol was comparable to that in a control subject similarly studied; it was also similar to that in a larger series of subjects studied previously (37). By contrast, there was virtually no incorporation into plasma phytanic acid (Figure 2). At 4 hours and 8 hours, the radioactivity recovered from the phytanic acid band on TLC was approximately $1 \%$ of the amount present in cholesterol at those times; at 24 and at 96 hours there was no detectable radioactivity in the phytanic acid zone. At 168 hours there was again a small amount of radioactivity isolated with phytanic acid, $10 \mathrm{cpm}$ per $\mathrm{ml}$ plasma, whereas the cholesterol fraction contained $179 \mathrm{cpm}$ per $\mathrm{ml}$. There was no radioactivity detectable in the phytanic acid zone from TLC in the control subject. As discussed above, the resolution of phytanic acid from other acidic lipids is incomplete by TLC, and the small amounts of radioactivity found in this zone in patient T.E. may not represent phytanic acid. Furthermore, there was no regular time course in the low levels of incorporation observed. The results indicate that biosyn- thesis from mevalonate must be very slow, if it occurs at all. Still, if biosynthesis were a very slow process, the level of incorporation after a single dose of labeled precursor might be too low to detect reliably. Moreover, the possibility of biosynthesis from low molecular weight precursors not involving isoprenoid units derivable from mevalonic acid also had to be considered. For these reasons a second, more general, test for biosynthesis with $\mathrm{D}_{2} \mathrm{O}$ was carried out in this subject.

The body water of patient T.E. was brought to approximately 0.5 atom $\%$ excess deuterium and maintained at that level for a period of 4 months. Deuterium enrichment in plasma cholesterol and in plasma phytanic acid was determined at intervals. There was progressive enrichment in plasma cholesterol, reaching a value of 0.223 atom $\%$ excess at 130 days. From the studies of Rittenberg and Schoenheimer (38), we can assume that half of the hydrogen atoms in cholesterol are ultimately derived from body water, and these 23 hydrogen atoms should show enrichment equal to that of the body water when a final steady state has been reached (neglecting contribution of exogenous cholesterol). After 130 days, the enrichment observed reached $91 \%$ of the theoretical maximum calculated on this basis. The data plotted in Figure 3 have been calculated based on the foregoing assumptions, i.e., that the deuterium in the molecule is distributed among only 23 of the hydrogen atoms. The postulated pathway for bio-

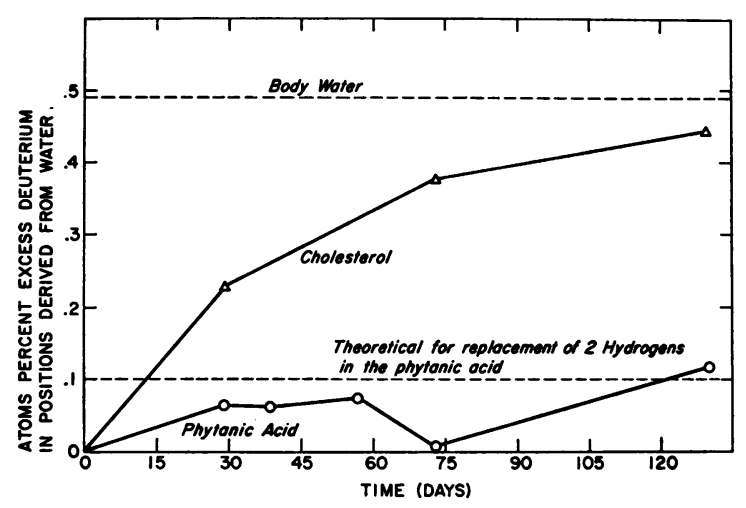

Fig. 3. DEUTERIUM ENRICHMENT IN POSITIONS DERIVED FROM BODY WATER IN PLASMA CHOLESTEROL AND PHYTANIC aCid in a patient (T.E.) with Refsum's disease. Total body water enrichment averaged 0.49 atom \% excess over the 130 days of study. See text for detailed explanation. 
synthesis of phytanic acid (Figure 1) would result in incorporation of 14 hydrogen atoms by reductive processes. As discussed below, this number is uncertain since it depends on the extent to which reduced nucleotides exchange with body water. To contrast the results with the cholesterol data, we have calculated and plotted in Figure 3 the incorporation into phytanate on the assumption that complete turnover would result in replacement of 2 of the 39 nonlabile hydrogen atoms in phytanic acid. (Since the methyl ester of phytanic acid was prepared for analysis, the readily exchangeable carboxyl hydrogen was not included in the data analyzed.)

As discussed under Methods, the enrichment in the fragment of the molecule representing carbons 1 through 3 together with the first branch-methyl group could be separately determined in the mass spectrometer. Analysis of the results shows that the small incorporation into the parent molecule observed was largely limited to this terminal fragment. In all of the samples analyzed for enrichment in the 102 fragment, we found that at least three-quarters of the deuterium in the total molecule had been incorporated at this end of the molecule. This might reflect 1 ) nonenzymatic exchange of the hydrogen adjacent to the carboxyl group; 2) enzymatically catalyzed exchange (desaturation-resaturation occurring in the 2,3 position) ; or 3) formation of phytanic acid from dietary phytol, a reaction involving hydrogenation of the 2,3 double bond of the latter, or from other unsaturated precursors. In any case, there was no evidence of regular distribution of deuterium along the chain, such as would be expected if phytanic acid were biosynthesized de novo from mevalonate or other low molecular weight precursors.

Metabolism of phytol- $U-{ }^{14} C$. Tracer doses (less than $0.5 \mathrm{mg}$ ) of phytol-U- ${ }^{14} \mathrm{C}$ in 20 to $30 \mathrm{ml}$ of vegetable oil were given orally to two patients with Refsum's disease and to seven normal control subjects. Absorption ranged from 61 to $94 \%$ in control subjects and was 74 and $80 \%$, respectively, in the two patients (Table II). A small percentage of the absorbed dose (4.7 to $13.4 \%$, mean $7.7 \%$ ) appeared in the urine during the first 24 hours. The urinary excretion measured in patient T.E. was $6.5 \%$ of the absorbed dose.

The rate of formation of ${ }^{14} \mathrm{CO}_{2}$ as a function of
TABLE II

Absorption, oxidation, and urinary excretion of phytol- $U-{ }^{14} C$ in patients with Refsum's disease and in normal control subjects

\begin{tabular}{lccc}
\hline & $\begin{array}{c}\text { Percentage } \\
\text { of dose } \\
\text { absorbed }\end{array}$ & $\begin{array}{c}\text { Percentage of } \\
\text { absorbed dose } \\
\text { converted to } \\
\text { Subject }\end{array}$ & $\begin{array}{c}\text { Percentage of } \\
\text { absorbed dose } \\
\text { excreted in }\end{array}$ \\
urine in 24 hours \\
Refsum's disease & & & \\
T.E. & 74 & 5.8 & 6.5 \\
K.M. & 80 & 3.5 & \\
Normal control & & & \\
J.C. & 94 & 29.1 & 5.8 \\
G.L. & 82 & 17.5 & 7.9 \\
R.B. & 61 & 20.6 & 9.7 \\
E.R. & 64 & 37.5 & 13.4 \\
E.J. & 66 & 3.2 & 5.0 \\
J.H. & 68 & 10.6 & 7.7 \\
J.L. & 89 & 28.0 & 4.7 \\
Mean for normal & & & \\
controls & 75 & 20.9 & 7.7 \\
\hline
\end{tabular}

time is shown in Figure 4. The total output in 12 hours averaged $20.9 \%$ in the control subjects, compared to 3.5 and $5.8 \%$ in the two patients. One control subject, E.J., excreted only $3.2 \%$ of the absorbed dose as ${ }^{14} \mathrm{CO}_{2}$. This subject was clinically normal, and no phytanic acid was detected in her plasma lipids. The reason for the low



Fig. 4. ${ }^{14} \mathrm{CO}_{2}$ Formation (ORdinate scale: $1 \times 10^{4}$ ) FROM PHYTOL-U- ${ }^{14} \mathrm{C}$ IN SEVEN CONTROL SUBJECTS ( $\bullet$ ) AND two patients ( $\Delta$ K.M., $\Delta$ T.E.) With Refsum's DISEASE. The solid line connects the mean values from the seven control subjects for each time point (samples were taken from only six control subjects at 9 hours); the rectangle encompassing each mean value represents the range of 2 SEM. 


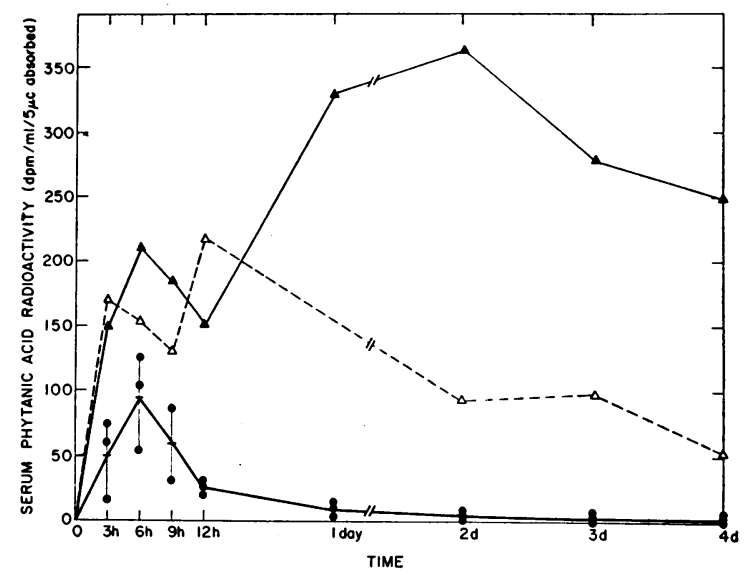

Fig. 5. Phytanic ACId $-{ }^{14} \mathrm{C}$ formation from PhytolU- ${ }^{14} \mathrm{C}$ IN THREE CONTROL SUBJECTS (@) AND TWO PAtients ( $\Delta$ K.M., $\Delta$ T.E.) With ReFsum's Disease. The mean values from the three control subjects for each time point are shown as cross bars; at 9 hours, samples were taken from only two control subjects.

value observed is not known. Technical error is possible, and a repeat study is planned.

Both in the normal control subjects and in the patients, radioactive phytanic acid was demonstrable in the plasma lipids after administration of labeled phytol (Figure 5). In the control subjects the labeled phytanic acid disappeared rapidly from the plasma, being almost completely gone by 24 hours. In contrast, labeled phytanic acid persisted at high levels in the patients' plasmas (Figure 5). Traces of fatty acid- ${ }^{14} \mathrm{C}$ were demonstrated in the plasma of patient K.M. as late as 90 days after the administration of phytol $-{ }^{14} \mathrm{C}$.

\section{Discussion}

The failure to find appreciable incorporation of mevalonic acid-2- ${ }^{14} \mathrm{C}$ into phytanic acid appears to rule out endogenous biosynthesis by way of the isoprenoid pathway as a significant source of the branched-chain fatty acid in the patient with Refsum's disease. Attempts to demonstrate endogenous biosynthesis from acetate or from mevalonate in normal rats and in phytol-fed rats have also been negative $(16,39)$.

Evaluation of the incorporation of $\mathrm{D}_{2} \mathrm{O}$ observed requires consideration of the postulated pathway of biosynthesis. If phytanic acid were synthesized from acetate by way of mevalonate and then conjugation of four isoprene units (Figure 1 ), one would anticipate that 14 hydrogen atoms could be derived from reductive processes. However, the exact number of hydrogens derived from body water is uncertain because of the lack of sufficient information on 1) the extent of equilibration of reduced nucleotides with $\mathrm{D}_{2} \mathrm{O}$ and 2) the extent of exchange of labile hydrogens in intermediates (40). Since at most 2 or 3 hydrogens were replaced by deuterium over a 4 -month period on $\mathrm{D}_{2} \mathrm{O}$, it can be immediately concluded that biosynthesis, if it occurs at all, must be extremely slow. Furthermore, the additional information obtained by analysis of the mass spectra, showing that enrichment was largely limited to the carboxyl-terminal fragment of the molecule (carbon atoms 1 through 3 together with the first branch-methyl group), strongly suggests that even the small incorporation observed does not reflect de novo synthesis. The latter should result in even distribution along the string of isoprene units. It could reflect exchange of hydrogen atoms alpha to the carboxyl carbon or reduction of unsaturated dietary precursors (such as phytol) to phytanic acid. The isotopic studies lead us to conclude that there is little or no endogenous biosynthesis from small molecules and that the phytanic acid accumulating must therefore have an exogenous origin. The results with phytol- ${ }^{14} \mathrm{C}$ establish it as a potential precursor.

Studies in this laboratory first demonstrated that normal experimental animals absorb dietary phytol and convert it to phytanic acid, and that the latter accumulates when phytol intake is high $(13,41)$. These results have been confirmed and extended by Klenk and Kremer (14). The present studies clearly establish that also in man dietary phytol-U- ${ }^{14} \mathrm{C}$ is readily absorbed and converted to phytanic acid, both in normal subjects and in patients with Refsum's disease. Conversion of tritium-labeled phytol to phytanic acid in a patient with Refsum's disease has been reported by Stoffel and Kahlke (42). When phytol is fed to rats at high dosages, phytanic acid accumulates in the tissues, accounting for as much as 20 to $30 \%$ of the total fatty acids in liver and serum $(13,14)$. Similar results have been obtained in the mouse, rabbit, and chinchilla (15). Dietary phytanic acid $(14,15,22,39)$ is also absorbed by the rat and, when fed in sufficiently high dosage, also leads to accumulation of phytanic acid in tissues. Finally it has been shown in rats that ${ }^{14} \mathrm{C}-$ 
labeled dihydrophytol is converted to phytanic acid $(16,43)$ and that feeding of dihydrophytol in large doses again causes accumulation of plytanic acid (14). It should be stressed that, in order to cause significant accumulation of phytanic acid in normal experimental animals, very large daily doses of the various branched-chain precursors must be administered, i.e., the normal animal has the capacity to metabolize large amounts of these substrates $(13-15,22,39)$.

It is possible that the enzymatic defect in Refsum's disease lies in an inability to hydrolyze esters of phytanic acid at a normal rate. If this were the case, phytanic acid originating in the diet might be incorporated into lipid esters in the patients' tissues and would then be only slowly released. The rate of release from ester forms might then become the rate-limiting step in phytanic acid degradation. This would explain a low rate of elimination of phytanic acid and a tendency to accumulate it and would be compatible with our phytol-U- ${ }^{14} \mathrm{C}$ results. Since, as shown in animal studies (16), phytol is rapidly converted to phytanic acid and the latter rapidly incorporated into esters, the rate of oxidation of the phytol- ${ }^{14} \mathrm{C}$ administered might very well have been limited in the present studies by such a limitation in ester hydrolysis. Since phytanic acid in the patient is found in all the major classes of lipid esters, it would seem to be necessary to postulate deficiencies in several different esterases. It is conceivable, however, that a deficiency in one specific type of esterase might lead secondarily to accumulation of phytanic acid in other ester classes because of interactions among the various esters.

The slower rate of conversion of labeled phytol to ${ }^{14} \mathrm{CO}_{2}$ in patients, as shown here, and the persistence of high levels of radioactive phytanic acid in the plasma are also compatible with the conclusion that patients with Refsum's disease have a metabolic block in the oxidation of phytanic acid. Interpretation of these results is made difficult, however, by the presence in the patients of large pools of unlabeled phytanic acid. It is necessary to consider whether the lower rate of appearance of ${ }^{14} \mathrm{CO}_{2}$ and the persistence of label in the plasma merely reflect dilution of the administered precursor in these unlabeled pools of phytanic acid. Although an unequivocal answer is difficult to obtain from these clinical studies, reference to some ancillary studies gives several reasons for believing that we are dealing here with a partial enzyme deficiency :

1) The fraction of a tracer dose of phytol-U- ${ }^{14} \mathrm{C}$ converted to ${ }^{14} \mathrm{CO}_{2}$ has been determined $a$ ) in control rats that have virtually no body pools of phytanic acid and $b$ ) in phytol-fed rats that accumulate body stores of phytanic acid comparable to or even larger than those found in patients with Refsum's disease. In both cases, about $30 \%$ of the absorbed dose was converted to ${ }^{14} \mathrm{CO}_{2}$ in the first day $(16,43)$. The degree to which the administered radioactivity was diluted by unlabeled stores of phytanic acid cannot be determined. Whatever the extent of dilution, the result shows that the normal rat had sufficient enzyme activity on the oxidative pathway to maintain the same fractional turnover of administered label in the presence of sizeable diluting pools as in the control state. Normal human subjects have been given tracer doses of phytol-U- ${ }^{14} \mathrm{C}$, as in the present studies, and on another occasion a $1-\mathrm{g}$ dose of phytol-U-14 $\mathrm{C}$ (44). Approximately $60 \%$ of the $1-\mathrm{g}$ dose was absorbed. The fraction of the dose converted to ${ }^{14} \mathrm{CO}_{2}$ when the large dose was given was just as great as when only the tracer dose was given. Thus, normal man has enough enzyme activity that saturation of oxidative capacity has not been reached at the $1-\mathrm{g}$ dose level.

2) Eldjarn, Try, and Stokke (45) have studied the metabolism of a model compound structurally related to phytanic acid, 3,6-dimethylcaprylic acid$8-{ }^{14} \mathrm{C}$. This was given to normal subjects and to subjects with Refsum's disease and the ${ }^{14} \mathrm{CO}_{2}$ output determined. After oral administration, normal subjects excreted 2 to $3 \%$ of the dose as ${ }^{14} \mathrm{CO}_{2}$ in 10 hours, whereas two patients with Refsum's disease completely failed to oxidize to ${ }^{14} \mathrm{CO}_{2}$ any of the substrate. Of course, if the pathway for degradation of the model compound parallels that for metabolism of phytanic acid, the question of competitive inhibition must still be considered, but the qualitatively different result again supports the presence of a metabolic block in a degradative pathway.

3 ) If the phytanic acid accumulating in Refsum's disease has an exogenous origin, and if the block in metabolism is incomplete, it should be possible to deplete body stores by appropriate 
dietary modifications. Preliminary results show that at least plasma phytanic acid concentrations can be depleted (9). Patients T.E. and K.M. were observed over the period of a year during which their diet was modified to exclude as much as possible foods containing phytanic acid or phytol. After an initial period of several months during which there was little change, the plasma phytanic acid concentration began to fall progressively and went down to levels about one-fourth of the initial values. This lipid storage disease thus appears to be similar to phenylketonuria in that the accumulation of the abnormal substance depends upon the intake of precursors in the diet.

On the basis of all data presently available, we conclude that accumulation of phytanic acid in Refsum's disease is most probably due to a partial block in its degradation. The pathway for oxidation of phytanic acid has not been established. ${ }^{5}$ and little can be said regarding the exact nature of the enzyme defect. Because the $\beta$-methyl substitution precludes direct $\beta$ oxidation, Eldjarn and coworkers have explored the possibility that an $\omega$-oxidizing system might be deficient in Refsum's disease. They have shown that in the $\omega$ oxidation of capric acid, patients do have a decreased capacity compared to that of normal controls (48). However, the patients' abilities to break down geraniol, 2,2-dimethylstearic acid, cholesterol, and vitamin $E$ by $\omega$ oxidation appeared to be normal (49). As discussed above, patients with Refsum's disease seem to have a complete block in the pathway for degradation of the model compound, 3,6-dimethyloctanoic acid (45). Eldjarn, Try, and Stokke have therefore proposed that there may be two alternative pathways for phytanic acid degradation, one of which is still intact and one of which is very closely related at some point to that for degrading 3,6-dimethyloctanoic acid and is completely blocked. Alternatively, the impaired rate of metabolism could be due to attenuated activity of a single degradative pathway.

It is not yet established that phytanic acid accumulation in itself leads to the neurological changes in Refsum's disease. Preliminary evidence compatible with such a direct effect has

\footnotetext{
5 Since this paper was submitted, it has been shown in experimental animals that phytanic acid undergoes an initial alpha oxidation to yield 2,6,10,14-tetramethylpentadecanoic acid (46) and that this then is degraded by successive beta oxidations (47).
}

been presented in connection with the dietary restriction studies referred to above, in which one patient showed some clinical improvement during the year on special diet (9). Such a direct relationship might follow because incorporation of the branched-chain compound into myelin might distort its structure and make the membranes unstable. However, in studies to date, it has not been possible to evoke changes in nerve structure or function by feeding phytol or phytanic acid to experimental animals $(15,39)$. Another possibility is that phytanic acid interferes with the function of fat-soluble vitamins with side-chains of more or less closely related structure (A, E, and $\mathrm{K})$. On the other hand, the symptoms might be unrelated to phytanic acid accumulation per se. One or more of the steps in phytanic acid degradation may involve enzymes that are important also in other metabolic pathways. Thus a deficiency might lead to accumulation of phytanic acid and simultaneously, although independently, to distortions of metabolic pathways critical for normal nerve structure and function. Finally, there is the possibility that more than one gene is affected and that the defect in phytanic acid degradation is not functionally related to the error in nerve cell metabolism.

\section{Acknowledgments}

The expert technical assistance of Mrs. E. L. Witherspoon and Mrs. B. E. Hom is gratefully acknowledged.

\section{References}

1. Refsum, S. Heredoataxia hemeralopica polyneuritiformis-a hitherto undescribed familial syndrome? Nord. Med. 1945, 28, 2682.

2. Refsum, S. Heredopathia atactica polyneuritiformis. A familial syndrome not hitherto described. A contribution to the clinical study of the hereditary diseases of the nervous system. Acta psychiat. scand. 1946 (suppl. 38), 9.

3. Richterich, R., H. Moser, and E. Rossi. Refsum's disease (heredopathia atactica polyneuritiformis): an inborn error of lipid metabolism with storage of 3,7,11,15-tetramethyl hexadecanoic acid. A review of the clinical findings. Humangenetik $1965,1,322$.

4. Richterich, R., S. Rosin, and E. Rossi. Refsum's disease (heredopathia atactica polyneuritiformis) : an inborn error of lipid metabolism with storage of $3,7,11,15$ tetramethyl hexadecanoic acid. Formal genetics. Humangenetik 1965, 1, 333. 
5. Klenk, E., and W. Kahlke. Über das Vorkommen der 3.7.11.15-Tetramethylhexadecansäure (Phytansäure) in den Cholesterinestern und anderen Lipoidfraktione der Organe bei einem Krankheitsfall unbekannter Genese (Verdacht auf Heredopathia atactica polyneuritiformis [Refsum-Syndrom]). Hoppe-Seylers Z. physiol. Chem. 1963, 333, 133.

6. Hansen, R. P. 3,7,11,15-Tetramethylhexadecanoic acid: its occurrence in the tissues of humans afflicted with Refsum's syndrome. Biochim. biophys. Acta (Amst.) 1965, 106, 304.

7. Richterich, R., W. Kahlke, P. van Mechelen, and E. Rossi. Refsum's Syndrom (Heredopathia atactica polyneuritiformis) : ein angeborener Defekt im Lipid-Stoffwechsel mit Speicherung von 3,7,11,15Tetramethyl-Hexadecansäure. Klin. Wschr. 1963, 41,800 .

8. Kahlke, W. Refsum-Syndrom-Lipoidchemische Untersuchungen bei 9 Fällen. Klin. Wschr. 1964, 42, 1011.

9. Eldjarn, L., K. Try, O. Stokke, A. W. Munthe-Kaas, S. Refsum, D. Steinberg, J. Avigan, and C. Mize. Dietary effects on serum phytanic-acid levels and on clinical manifestations in heredopathia atactica polyneuritiformis. Lancet 1966, 1, 691.

10. Bloch, K. The biological synthesis of cholesterol. Science 1965, 150, 19.

11. Grob, E. C., K. Kirschner, and F. Lynen. Neues über die Biosynthese der Carotinoide. Chimia 1961, 15, 308.

12. Nandi, D. L., and J. W. Porter. The enzymatic synthesis of geranyl geranyl pyrophosphate by enzymes of carrot root and pig liver. Arch. Biochem. 1964, 105, 7.

13. Steinberg, D., J. Avigan, C. Mize, and J. Baxter. Phytanic acid formation and accumulation in phytolfed rats. Biochem. biophys. Res. Commun. 1965, 19, 412.

14. Klenk, E., and G. J. Kremer. Untersuchungen zum Stoff wechsel des Phytols, Dihydrophytols und der Phytansäure. Hoppe-Seylers Z. physiol. Chem. 1965, 343, 39.

15. Steinberg, D., J. Avigan, C. E. Mize, J. H. Baxter, J. Cammermeyer, H. M. Fales, and P. F. Highet. Effects of dietary phytol and phytanic acid in animals. J. Lipid Res. 1966, 7, 684.

16. Mize, C. E., J. Avigan, J. H. Baxter, H. M. Fales, and D. Steinberg. Metabolism of phytol-U- ${ }^{14} \mathrm{C}$ in the rat. J. Lipid Res. 1966, 7, 692.

17. Sonneveld, W., P. Haverkamp Begemann, G. J. van Beers, R. Keuning, and J. C. M. Schogt. 3,7,11,15Tetramethylhexadecanoic acid, a constituent of butter fat. J. Lipid Res. 1962, 3, 351.

18. Hansen, R. P. Occurrence of 3,7,11,15-tetramethylhexadecanoic acid in ox perinephric fat. Chem. and Industr. 1965, 7, 303.

19. Hansen, R. P. 3,7,11,15-Tetramethylhexadecanoic acid: its occurrence in sheep fat. N. Z. J. Sci. 1965, 8, 158.
20. Avigan, J. The presence of phytanic acid in normal human and animal plasma. Biochim. biophys. Acta (Amst.) 1966, 116, 391.

21. Kremer, G. J. Über das Vorkommen der 3,7,11,15Tetramethylhexadecansäure in den Lipoiden von Normalseren. Klin. Wschr. 1965, 43, 517.

22. Hansen, R. P., F. B. Shorland, and I. A. M. Prior. The fate of phytanic acid when administered to rats. Biochim. biophys. Acta (Amst.) 1966, 116, 178.

23. Steinberg, D., J. Avigan, C. Mize, L. Eldjarn, K. Try, and S. Refsum. Conversion of $\mathrm{U}-\mathrm{C}^{\mathbf{1 4}}$-phytol to phytanic acid and its oxidation in heredopathia atactica polyneuritiformis. Biochem. biophys. Res. Commun. 1965, 19, 783.

24. Steinberg, D., C. Mize, J. Avigan, H. M. Fales, L. Eldjarn, K. Try, O. Stokke, and S. Refsum. On the metabolic error in Refsum's disease. J. clin. Invest. 1966, 45, 1076.

25. Steinberg, D., C. Mize, J. Avigan, H. M. Fales, L. Eldjarn, K. Try, O. Stokke, and S. Refsum. On the metabolic error in Refsum's disease. Trans. Amer. neurol. Ass. 1966, 91, 168.

26. Steinberg, D. A new approach to radioassay of aqueous solutions in the liquid scintillation spectrometer. Analyt. Biochem. 1960, 1, 23.

27. Nathan, D. G., J. D. Davidson, J. G. Waggoner, and N. I. Berlin. The counting of barium carbonate in a liquid scintillation spectrometer. J. Lab. clin. Med. 1958, 52, 915.

28. Woeller, F. H. Liquid scintillation counting of $\mathrm{C}^{14} \mathrm{O}_{2}$ with phenethylamine. Analyt. Biochem. 1961, 2, 508.

29. Bray, G. A. A simple efficient liquid scintillator for counting aqueous solutions in a liquid scintillation counter. Analyt. Biochem. 1960, 1, 279.

30. Jover, A., and R. S. Gordon, Jr. Procedure for quantitative analysis of feces with special reference to fecal fatty acids. J. Lab. clin. Med. 1962, 59, 878.

31. Baxter, J. H. Personal communication.

32. Folch, J., M. Lees, and G. H. Sloane Stanley. A simple method for the isolation and purification of total lipides from animal tissues. J. biol. Chem. 1957, 226, 497.

33. Total cholesterol procedure N-24 in Autoanalyzer Manual. Chauncey, N. Y., Technicon Instruments Corp., 1964.

34. Stewart, C. P., and E. B. Hendry. The phospholipins of blood. Biochem. J. 1935, 29, 1683.

35. Jagannathan, S. N. The determination of plasma triglycerides. Canad. J. Biochem. 1964, 42, 566.

36. Nakanishi, K. Infrared Absorption Spectroscopy. San Francisco, Holden-Day, 1962, p. 65.

37. Steinberg, D., J. Avigan, and E. B. Feigelson. Effects of triparanol (MER-29) on cholesterol biosynthesis and on blood sterol levels in man. J. clin. Invest. 1961, 40, 884.

38. Rittenberg, D., and R. Schoenheimer. Deuterium as an indicator in the study of intermediary metabo- 
lism. XI. Further studies on the biological uptake of deuterium into organic substances, with special reference to fat and cholesterol formation. J. biol. Chem. 1937, 121, 235.

39. Avigan, J., D. Steinberg, and J. Cammermeyer. Phytol and phytanic acid metabolism in relation to Refsum's disease. Fed. Proc. 1966, 25, 522.

40. Foster, D. W., and B. Bloom. The synthesis of fatty acids by rat liver slices in tritiated water. J. biol. Chem. 1963, 238, 888.

41. Steinberg, D., J. Avigan, C. Mize, and J. H. Baxter. Phytanic acid formation and accumulation in phytol-fed rats. Fed. Proc. 1965, 24, 290.

42. Stoffel, W., and W. Kahlke. The transformation of phytol into 3,7,11,15-tetramethylhexadecanoic (phytanic) acid in heredopathia atactica polyneuritiformis (Refsum's syndrome). Biochem. biophys. Res. Commun. 1965, 19, 33.

43. Mize, C. E., J. Avigan, J. H. Baxter, and D. Steinberg. Metabolism of phytol and phytanic acid. Fed. Proc. 1966, 25, 522.

44. Mize, C. E., D. Steinberg, and J. Avigan. Unpublished observations.
45. Eldjarn, L., K. Try, and O. Stokke. The existence of an alternative pathway for the degradation of branch-chained fatty acids, and its failure in heredopathia atactica polyneuritiformis (Refsum's disease). Biochim. biophys. Acta (Amst.) 1966, 116, 395.

46. Avigan, J., D. Steinberg, A. Gutman, C. E. Mize, and G. W. A. Milne. Alpha-decarboxylation, an important pathway for degradation of phytanic acid in animals. Biochem. biophys. Res. Commun. 1966, 24, 838.

47. Mize, C. E., D. Steinberg, J. Avigan, and H. Fales. A pathway for oxidative degradation of phytanic acid in mammals. Biochem. biophys. Res. Commun. 1966, 25, 359.

48. Eldjarn, L. Heredopathia atactica polyneuritiformis (Refsum's disease) - a defect in the omega-oxidation mechanism of fatty acids. Scand. J. clin. Lab. Invest. 1965, 17, 178.

49. Eldjarn, L., K. Try, and O. Stokke. The ability of patients with heredopathia atactica polyneuritiformis to $\omega$-oxidize and degrade several isoprenoid branch-chained fatty structures. Scand. J. clin. Lab. Invest. 1966, 18, 141. 